\title{
Una rebelión sumisa - las mujeres en el Estado Islámico
}

\author{
A submissive rebellion - women in the Islamic State \\ Eliane Ursula ETTMUELLER \\ Heidelberg Center for Transcultural Studies \\ ettmueller@asia-europe.uni-heidelberg.de
}

Recibido 26/4/2018. Revisado y aprobado para publicación 15/6/2018

\begin{abstract}
Para citar este artículo: Eliane Ursula ETTMUELLER (2018), "Una rebelión sumisa - las mujeres en el Estado Islámico" en Revista de Estudios Internacionales Mediterráneos, 24, 129-150.

Para acceder a este artículo: https://doi.org/10.15366/reim2018.24.008
\end{abstract}

\section{Resumen}

A primera vista, la situación de las mujeres en el así llamado "Estado Islámico" (EI), que se autoproclamó como nuevo califato a finales del mes de junio de 2014, parece completamente insoportable. Las prescripciones vestimentarias superan incluso las de los talibanes en los años noventa; a las niñas se les puede casar a los nueve años y, por si fuera poco, el grupo extremista emitió reglas sobre el trato de esclavas domésticas y sexuales. Así, parece increíble que existan mujeres que apoyan al El y su devastadora política de género. Sin embargo, las estadísticas demuestran que de las personas que abandonaron su hogar en Europa para integrarse a las filas del El hasta un 20 por ciento son mujeres o chicas menores de edad. Este artículo explora su motivación e indaga la capacidad que la propaganda del El tiene para seducir a las mujeres. Asimismo, esclarece cómo es que las seguidoras juegan un papel importante para el desarrollo de este grupo extremista comparando el rol que se les atribuye a las mujeres en el seno de otros movimientos islamistas.

Palabras claves: mujeres del Estado Islámico, islamismo femenino, extremismo islámico, propaganda islamista 


\begin{abstract}
At a first glance, the situation of women in the so-called "Islamic State" (IS), which proclaimed itself as a new caliphate by the end of June 2014, seems completely unbearable. Dress code regulations are even more restrictive than the ones introduced by the Taliban in the 1980s. Additionally, the extremist group issued rules about how to treat domestic and sexual slaves. Consequently, it seems difficult to believe that there are women who may support IS and the devastating gender policy it stands for. However, statistics show that among the people who left their European homes in order to join the ranks of IS there are up to $20 \%$ women and girls. This article researches into their motivation and into the appeal the IS has to attract women. At the same time, it clarifies how these female followers play an important role on the evolution of this extremist group, when compared to women of other Islamist movements.
\end{abstract}

Key words: women in the Islamic State, female Islamism, Islamic extremism, Islamist propaganda

\title{
Introducción
}

De la amplia literatura sobre el El, ${ }^{1}$ sólo pocas autoras y autores han dedicado sus estudios a la propaganda islamista hecha y distribuida por mujeres. Una excepción es el estudio de Olga Torres Díaz, que analiza la comunicación oficial y oficiosa de las mujeres del El (Torres Díaz, 2015). Su análisis se centra en publicaciones de propagandistas del El hasta el mes de noviembre de 2015.

Con el propósito de comprehender la motivación femenina de participar en movimientos islamistas extremistas como el El o Al Qaida, ${ }^{2}$ publicaciones firmadas por mujeres que circularon por internet fueron consultadas (textos, audios y videos) y evaluadas para el presente estudio. La investigadora partió de la hipótesis que dentro de la visión del mundo islamista que impone una nítida segregación sexual debe de existir un razonamiento particular femenino que justifica la implicación de las mujeres en las filas islamistas.

En un reportaje de Expressen publicado en Youtube el 14 de marzo de $2014^{3}$ dos mujeres originarias de Raqqa -llamadas Umm Umran y Umm Muhammad4- muestran su ciudad bajo el régimen del El a través de una cámara camuflada. Entran en una tienda y encuentran paquetes de tinte de pelo donde las caras de las mujeres han sido borradas. El vendedor argumenta que las modelos en los paquetes de tinte llevan un niqab, un velo integral que tapa todo el cuerpo salvo los ojos. Unos minutos después las dos reporteras clandestinas son reprendidas por un policía de la hisba, la policía de la virtud, el cual les señala que deben ir bien tapadas. Una de las mujeres

\footnotetext{
${ }^{1}$ Como contribución importante al respecto en castellano se puede citar el libro de Javier Martín El Estado Islámico: Geopolítica del Caos (Martín, 2015).

2 Según un estudio del Real Instituto Elcano sobre las facetas de la actual movilización terrorista en España (entre el año 2013 y el noviembre de 2015) de las personas detenidas por actividades relacionadas con el terrorismo yihadista, un 15,8 por ciento fueron mujeres (García-Calvo y Reinares, 2015).

3 "Inside Raqqa: Women's secret films from within closed city of terrorist sect ISIS", Expressen, 14 de marzo de 2014 , https://www.youtube.com/watch?v=V28SDigCLek [consulta: 1 de noviembre de 2017].

${ }^{4}$ En lo que corresponde a los nombres de personas u organizaciones, la autora usa la transcripción desde la fuente árabe al alfabeto latino usada por estas mimas o la más común en castellano.
} 
concluye que su feminidad y su libertad les han sido robadas por completo y que desean profundamente volver a salir de manera libre y sin el protector masculino obligatorio llamado mahram. ${ }^{5}$

Más terrible aún son los testimonios de las mujeres yazidíes -una minoría religiosa- que, luego de ser raptadas en sus casas al noroeste del Iraq por los combatientes del El, fueron vendidas como esclavas, maltratadas y violadas. El profesor de psicología alemán de origen kurdo Jan Ilhan Kizilhan viajó a Iraq para brindarles atención psicológica y también trató a un gran número de ellas en Alemania. Su libro sobre la psicología del El más que explicar el porqué de la actuación de los verdugos cuenta con detalle los horrores por los que pasaron estas mujeres al ser separadas de sus familias, obligadas a ver morir a sus hijos, vendidas, maltratadas y violadas en repetidas ocasiones (Kizilhan, 2017). En castellano, la periodista Ángela Rodicio también describe las condiciones inhumanas que padecieron las personas en Siria y en Iraq a través de múltiples testimonios de mujeres que conocieron el El desde dentro (Rodicio, 2016).

Desde su establecimiento como un califato sui géneris a finales del mes de junio de 2014, el El ha criticado furiosamente a la prensa internacional por distorsionar la realidad que viven sus habitantes y combatientes. Lo que puede sorprender a primera vista es que con ello los portavoces del EI se refieren a su superioridad moral, que supuestamente les ha sido otorgada por el mismísimo Dios. La prensa internacional les enfureció por no haber apoyado su reivindicación de encarnar el califato y la verdadera y única morada del islam (dar al-islam), donde sus habitantes viven felizmente a no ser que sean molestados por las bombas de los kuffar. ${ }^{6}$ En ningún momento han intentado negar sus actos violentos; por el contrario, estos incluso fueron publicados en videos de propaganda mediante los cuales ganaron aún más seguidores. La estrategia ha sido más bien justificar lo malo por un fin superior: la umma, la comunidad perfecta musulmana, y el paraíso que les espera a todos. Por ello es necesario aplicar la sharía, la ley de Dios. El mismo discurso también se manifestó en la temática de las esclavas sexuales. Los autores y sobre todo las autoras del El no negaron que aquello hubiera ocurrido sino que lo justificaron con su interpretación de la ley divina.

En diciembre de 2014 el "Departamento de Fetuas y Estudios" del El emitió un reglamento para el mantenimiento de esclavas sexuales. ${ }^{7}$ Según este folleto de dos hojas estructurado en preguntas y respuestas, las mujeres esclavas son sexualmente permisibles para los hombres por haber sido capturadas en tierras de infieles y distribuidas por el Imam. De acuerdo a estas reglas es lícito

\footnotetext{
${ }^{5}$ El mahram puede ser el marido o bien un hombre que no se puede casar con la mujer por la relación de parentesco que tiene con ella. Para facilitar la lectura de este artículo al público que no sabe árabe, la transcripción de términos árabes al castellano se guía por similitudes fonéticas de ambas lenguas. Se usan puntos diacríticos únicamente para reproducir las letras 'ayn $(\varepsilon)$ y hamza $(\varepsilon)$.

6 Por ejemplo: Wilayat ar-Raqqa, "Message to the Knights of the Media", 8 de marzo de 2015. http://jihadology.net/2015/03/08/new-video-message-from-the-islamic-state-message-to-the-knights-of-the-mediawilayat-al-raqqah/ [consulta: 1 de noviembre de 2017], Al-Hayat Media Centre, "From Inside Halab", 9 de febrero de 2015 [consulta: 4 de febrero de 2018]. http://jihadology.net/2015/02/09/al-\%E1\%B8\%A5ayat-media-center-presentsa-new-video-message-from-the-islamic-state-from-inside-\%E1\%B8\%A5alab/[consulta: 3 de marzo de 2018]

7 Su'al wa-yawab fi l-saby wa-r-riqab (Preguntas y respuestas sobre la toma de prisioneros y esclavos) (muharram 1436 (octubre o noviembre de 2014), Maktabat al-himma.
} 
tener como esclavas a las mujeres del kufr asli (infieles de origen) que se subclasifican en kitabiyyat ("mujeres del libro", judías y cristianas) y mushrikat (lit. "asociadoras" o lo que se entiende como politeístas). En lo que corresponde a las apóstatas, en el folleto se señala que los responsables del El tienden a no permitir su uso como esclavas por la falta de consenso entre los eruditos del islam en esta materia. Para permitir las relaciones sexuales con sus esclavas, los ideólogos del El citan el Corán (C 23:5-6). ${ }^{8}$ Además, se estipula que sólo el hombre que las posee puede mantener relaciones sexuales con ellas. También se declara lícito el abuso sexual de las menores con la condición ambigua de que deberían estar "listas para ello." ${ }^{2}$ El folleto también señala que las mujeres esclavas no tienen que llevar el velo y que se les puede golpear para disciplinarlas en el cuerpo pero no en la cara. Con esos detalles los representantes del El quieren demostrar que no defienden una situación de completa anarquía, sino que siguen las líneas supuestamente claras, racionales y queridas por Dios. La misma dinámica la demuestran en sus videos de ejecuciones, donde invariablemente argumentan que las personas ejecutadas fueron juzgadas y declaradas culpables por un tribunal de la sharía. Por consiguiente, el El hace un inmenso esfuerzo por demostrar que no mata por matar ni viola por violar, sino que lo hace con un fin superior.

En cuanto a las seguidoras del El estas no parecen estar menos convencidas que los hombres del carácter divino de estas reglas. Umm Sumayyah al-Muhajirah, la autora de las columnas "Para las hermanas" o "De las hermanas" de la revista de lengua inglesa Dabiq, justifica el uso de la esclavitud en su artículo intitulado "¿Chicas esclavas o prostitutas?". ${ }^{10}$ Siguiendo la argumentación salafista Umm Sumayyah al-Muhajirah retoma primero las fuentes de la religión más importantes. Para ello cita azoras del Corán ${ }^{11}$ y luego ejemplos de hadices coleccionados por Bujari y Muslim.

Según Umm Sumayyah al-Muhajira, el principio del saby (lo que se traduce como "capturar esclavos durante la guerra") es una gran sunna del profeta Muhammad. Después de citar algunos hadices adicionales de Bujari y Muslim justifica su argumento mediante ejemplos de la historia islámica, como cuando el profeta Muhammad y sus compañeros tomaron por esclavas a las mujeres de las tribus judías y politeístas que habían sido derrotadas por ellos. Continúa diciendo que "finalmente, por gracia divina, el Estado Islámico ha reinstaurado los castigos islámicos [que

\footnotetext{
8 "Se preserven de cometer adulterio o fornicación, y sólo cohabiten con sus esposas o con sus esclavas, pues ello no es censurable." Se usa para las citas coránicas la traducción de la página web Nur el-islam porque se presentan alineados el texto en árabe y la traducción al castellano. http://www.nurelislam.com/Los-Creyentes.

${ }_{9}$ Su'al wa-yawab fi l-saby wa-r-riqab (Preguntas y respuestas sobre la toma de prisioneros y esclavos) (muharram 1436 (octubre o noviembre de 2014)), maktabat al-himma.

${ }^{10}$ Umm Sumayyah al-Muhajirah (sha'ban 1436 (mayo o junio de 2015)): "From Our Sisters: Slave-Girls or Prostitutes", Dabiq, They Plot and Allah Plots, número 9, pp. 44-49.

${ }^{11}$ C 4:3: "Si teméis no ser equitativos con las huérfanas, entonces casaos con otras mujeres que os gusten: dos, tres o cuatro. Pero si teméis no ser justos, casaos con una sola o recurrid a vuestras esclavas. [...]"; C 24:3: "El hombre que haya fornicado sólo habrá podido hacerlo con una fornicadora igual que él o una idólatra, y la mujer que haya fornicado sólo habrá podido hacerlo con un fornicador igual que ella o un idólatra. Y [sabed que] se les ha prohibido a los creyentes la fornicación"; C 24:32: "Desposad a aquellos hombres o mujeres que no tengan cónyuge, y a vuestros esclavos y esclavas piadosos. [No temáis] Si son pobres, pues Allah les sustentará con Su gracia, y Él es Vasto, Omnisciente"; C 23:5-6: "Se preserven de cometer adulterio o fornicación, Y sólo cohabiten con sus esposas o con sus esclavas, pues ello no es censurable"; y C 2:221: "Y no os caséis con las idólatras a menos que acepten la fe; una esclava creyente es mejor que una idólatra, aunque os guste, y no caséis a los idólatras con vuestras mujeres a menos que acepten la fe; un esclavo creyente es mejor que un idólatra, aunque os guste. Ellos conducen al Infierno, mientras que Allah os promete el Paraíso con Su anuencia y el perdón, y aclara Sus preceptos a los hombres para que recapaciten."
} 
se encontraban en] la oscuridad de los libros y papeles." 12 Y afirma que los habitantes del El "los han vivido de verdad después de que estos han estado enterrados por tantos siglos."13 Se indigna frente al hecho de que después de todo eso se esté intentando menospreciar e insultar la sunna del profeta y la norma de la sharía que se llama saby. En este contexto le incomodan sobre todo los que según ella pretenden ser musulmanes, pero sólo lo son por sus nombres, y algunos seguidores del El:

"Lo que verdaderamente me inquietó fue que algunos de los seguidores del Estado Islámico (que Dios les perdone) intentaran defender al Estado Islámico -que su honor siga y que Dios proteja su territorio- después de que los medios de comunicación kafir ${ }^{14}$ comunicaran que el Estado Islámico había capturado a las mujeres yazidíes. Por consiguiente, los seguidores empezaron a negar este hecho como si los soldados del jilafa ${ }^{15}$ hubieran cometido un error o hecho algo malo. Sí, Allah abrió los países a sus awliya'16, para que entraran y se dispersaran [en ellos], matando a los combatientes de los kuffar, capturando a sus mujeres y tomando a sus niños como esclavos. Escribo eso mientras las letras gotean de orgullo. Sí, oh, todas las religiones del kufr, asaltamos y capturamos a las mujeres kafiras y las arreamos a punta de sable. [...] ¿o pensaron tú y tus seguidores que bromeábamos el día que anunciamos el jilafa según la metodología profética?"17

La autora del El concluye que el califato debe traer consigo honor para los musulmanes y humillación para los kuffar. No obstante, insiste en que no son los combatientes y seguidores del El los que humillan a los kuffar, sino que es Dios mismo quien lo hace. Añade que dado que los enemigos (se refiere sobre todo a los teólogos saudíes) declararon que la yihad no era una obligación de Dios y no explicaron nada sobre el principio del rechazo de un taghut (tirano), no sorprende que mientan acerca del saby (esclavitud). Además, insiste en que el saby no está hecho por simple placer. Según sus argumentos, Dios hizo posible la captura de esclavos en las tierras del kufr para la salvación de sus almas, ya que muchas se convierten posteriormente por su propia voluntad al islam. Esto ocurre en su opinión porque Dios mandó a los musulmanes de tratar bien hasta a los esclavos. Concluye preguntando:

“¿Qué es mejor, las chicas esclavas que tomamos por la ley de Dios o las prostitutas - un mal que vosotros no denunciáis -, quienes son tomadas por casi hombres en los países del kufr donde vivís? Una prostituta en vuestros países viene y va, cometiendo un pecado abiertamente. Vive de vender su honra a la vista y al oído de los teólogos desviados de los cuales no escuchamos ni el menor ruido [sobre este asunto]. En cuanto a la chicha esclava

\footnotetext{
12 Umm Sumayyah al-Muhajirah (sha'ban 1436 (mayo o junio de 2015)): "From Our Sisters: Slave-Girls or Prostitutes", Dabiq, They Plot and Allah Plots, número 9, p. 45.

${ }^{13}$ Umm Sumayyah al-Muhajirah (sha'ban 1436 (mayo o junio de 2015)): "From Our Sisters: Slave-Girls or Prostitutes", Dabiq, They Plot and Allah Plots, número 9, p. 45.

${ }^{14}$ Kafir, plur. kuffar quiere decir "infiel", "no creyente" o "persona que oculta la verdad (divina)". Aquí se usa sólo como "infiel".

15 Jilafa quiere decir "califato".

${ }^{16}$ Awliya' se refiere a la gente más honrada.

${ }_{17}$ Umm Sumayyah al-Muhajirah (sha'ban 1436 (mayo o junio de 2015)): "From Our Sisters: Slave-Girls or Prostitutes", Dabiq, They Plot and Allah Plots, número 9, pp. 45-46.
} 
que fue tomada por los sables de los hombres que siguieron al feliz combatiente Muhammad (sallahu alayhi wa-sallam), ¿su esclavitud va entonces en contra de los derechos humanos y la copulación con ella es una violación? ¿Cómo llegan a tales juicios? ¿Cuál es vuestra religión? ¿Cuál es vuestra ley? ¿Decidme, quién es vuestro señor?"18

Lo sorprendente en esta argumentación es que la autora da un giro completo a los conceptos éticos convencionales. Por encima de lo que Hannah Arendt había descrito como una banalización de la maldad por los nazis, que concibieron el genocidio de los judíos como un mal menor aunque seguía siendo un mal- que debía cometerse, los ideólogos del El convierten sus actos violentos en una virtud prescrita por Dios. Por consiguiente, les resulta completamente justo violar a una esclava yazidí y se asombran de que hasta una buena parte de los salafistas más radicales no lleguen a la misma conclusión. Los partidarios del El no intentan camuflar sus crímenes de guerra porque están firmemente convencidos de que se trata de la justicia divina por fin realizada en la tierra.

\section{Las mujeres en el El}

Ya vimos por el personaje de Umm Sumayyah al-Muhajirah que las mujeres del El comparten sus pensamientos con el mundo. En los quince números de la revista Dabiq se publicaron siete artículos sobre asuntos considerados de importancia para el sexo femenino. Se cubrieron los asuntos siguientes: la hiyra ${ }^{19} \sin$ mahram, ${ }^{20}$ las esclavas sexuales, ${ }^{21}$ el papel de la mujer en la yihad, ${ }^{22}$ la poligamia ${ }^{23}$ y el luto por el marido difunto. ${ }^{24}$ Todos los artículos fueron firmados por Umm Sumayyah al-Muhajirah, quien además hizo una llamada a las mujeres de los soldados de los sahawat para que abandonaran a sus esposos y a sus familias y se aliaran con el El. ${ }^{25}$ El primer artículo para mujeres fue una entrevista a Umm Basir al-Muhajirah, ${ }^{26}$ la esposa del terrorista Amedy Coulibaly, quien mató a varias personas en un supermercado kosher y a una policía en París en el mes de enero de 2015.

\footnotetext{
18 Ibíd., pp. 48-49.

${ }^{19}$ Con hiyra se hace alusión a la migración (hégira) del Profeta Muhammad a Yathrib (Medina) que dio comienzo al calendario musulmán. Las seguidoras y los seguidores del El comparan su viaje a los territorios bajo control del grupo extremista con aquel acontecimiento de gran importancia religiosa e histórica.

${ }^{20}$ Umm Sumayyah al-Muhajirah (yumada al-ajira 1436 (marzo o abril de 2015)): "To Our Sisters: The Twin Halves of the Muhajirin", Dabiq, Shari'a Alone Will Rule in Africa, número 8, pp. 32-37.

${ }^{21}$ Umm Sumayyah al-Muhajirah (sha'ban 1436 (mayo o junio de 2015)): "From Our Sisters: Slave-Girls or Prostitutes", Dabiq, They Plot and Allah Plots, número 9, pp. 44-49.

22 Umm Sumayyah al-Muhajirah (dhul al-qa'da 1436 (agosto o septiembre de 2015)): "To Our Sisters: A Jihad without Fighting", Dabiq, From the Battle of al-Ahzab to the War of Coalitions, número 11, pp. 40-45.

${ }^{23}$ Umm Sumayyah al-Muhajirah (safar 1437 (noviembre o diciembre de 2015)): "To Our Sisters: Two, Three or Four", en: Dabiq: Just Terror, número 12, pp. 19-22.

${ }^{24}$ Umm Sumayyah al-Muhajirah (rabi' al-ajir 1437 (enero o febrero de 2016)): "To Our Sisters: Advice on Ihdad" Dabiq: The Rafidah from Ibn Saba' to the Dajjal, número 13, pp. 24-27.

${ }^{25}$ Umm Sumayyah al-Muhajirah (ramadán 1436 (junio o julio de 2015)): "From Our Sisters: They Are Not Lawful Spouses for One Another", Dabiq, The Law of Allah or the Laws of Men, número 10, pp. 42-48.

${ }^{26}$ Anónimo (rabi" al-ajir 1436 (enero o febrero de 2015)): "To Our Sisters: A Brief Interview with Umm Basir alMuhajirah" Dabiq, From Hypocrisy to Apostasy the Extinction of a Gray Zone, número 7, pp. 50-51.
} 
Una descripción más detallada de lo que el El quiere para sus mujeres apareció a finales del año $2014^{27}$ en los foros islamistas. En esta fecha la agencia de comunicación de la compañía de mujeres del El (Sariyat al-Jansa') presentó un texto con el título "Las mujeres en el Estado Islámico". ${ }^{28} \mathrm{El}$ texto fue escrito en árabe y consta de tres partes. La primera parte se dedica al papel de la mujer en el nuevo califato, la segunda recoge ejemplos de las ciudades del nuevo Estado y el tercero anima a las hermanas saudíes a abandonar su patria, la cual es denunciada como moralmente corrupta, y a emigrar al nuevo califato. Con la modestia que se les pide a las mujeres del El, las autoras declaran en la introducción que no se trata de un documento oficial o de una especie de constitución sino que sólo quieren orientar a las mujeres. No obstante, se trata del texto más antiguo y más extenso (37 páginas en su original árabe) que ha intentado presentar desde el punto de vista femenino lo que significa el califato del El para las mujeres.

En la introducción las autoras celebran la restauración de un Estado islámico transfronterizo entre Siria e Iraq con el único fin de servir a Dios. Una sociedad como la que existía en los tiempos del profeta Muhammad y sus compañeros se estaría nuevamente desarrollando en la opinión de estas embajadoras del califato. Según ellas, las mujeres habrían jugado un papel importante en el pasado lejano de la historia musulmana y lo estarían haciendo también ahora.

Las autoras señalan que su panfleto se basa en el Corán y en la Sunna y citan asimismo el libro Realidad de la civilización islámica del salafista Sheij Nasir al-Fahd, en el cual el autor sostiene que el único saber verdadero proviene de la religión y está contenido en el Corán, en la Sunna y en la teología de los Salaf as-Salih. ${ }^{29}$ Las autoras deducen todos los problemas de los musulmanes en los tiempos actuales de dos fuentes principales: En primer lugar, estos han olvidado que la única razón de su existencia consiste en la glorificación de Dios. En segundo lugar, no han entendido el principio fundamental de al-wala' wa-l-bara' (lealtad y distanciamiento) por lo cual "mantienen relaciones de amistad con los infieles beligerantes y se benefician de su saber secular que no tiene ningún valor en la vida del más allá." 30 La ética dicotómica de al-wala' wa-l-bara' es importante en la retórica de los salafistas y de los yihadistas, que buscan distanciarse de todas las personas que no pertenece a su grupo de fieles. Los yihadistas hacen un amplio uso del argumento del distanciamiento de los infieles para fomentar la guerra en su contra.

Siguiendo la retórica salafista, las autoras recomiendan a sus hermanas guiarse por la vida de las primeras mujeres religiosas, María, Asia, Jadiya, Fátima, Aisha, y las mujeres de los compañeros del profeta Muhammad. También sostienen que Dios creó a la mujer de una costilla de Adán y para él. Por consiguiente, la tarea más importante de la mujer es la de ser una buena esposa para su marido. Las autoras de la compañía de mujeres justifican su conclusión mediante la cita de un

\footnotetext{
${ }^{27}$ Charlie Winter menciona erróneamente el 23 de enero de 2015 como fecha de publicación (Winter, 2015, p. 5). Sin embargo, el manifiesto fue publicado en justpaste.it a finales de 2014.

${ }^{28}$ Sariyat al-Jansa' al-i'lamiyya (invierno de 2014): al-mara' fi ad-dawla al-lslamiyya, justpaste.it.

29 Los Salaf as-Salih son los virtuosos ancestros, las primeras generaciones musulmanas por cuyos actos se guían los salafistas.

${ }^{30}$ Sariyat al-Jansa' al-i'lamiyya (invierno de 2014): al-mara' fi ad-dawla al-lslamiyya, justpaste.it, p. 7.
} 
hadiz de Ibn Hanbal que dice lo siguiente: "Si una mujer dice sus cinco [oraciones], ayuna su mes, se mantiene casta y obedece a su marido, le dirán: ¡Entra al paraíso por la puerta que quieras!"31

Después de los argumentos religiosos, el texto se sirve de deliberaciones biologicistas arguyendo que el papel de la madre y ama de casa corresponde a la naturaleza de la mujer. Es ampliamente conocido que los textos de los extremistas islámicos cuentan con bibliotecas enteras para culpar a las mujeres y sus fuerzas seductoras de los conflictos (fitna) entre los hombres. Sin embargo, las mujeres del El nos sorprenden al tomar la lógica del sexo culpable al revés. Dicen que las mujeres ya no pueden ser mujeres como Dios manda porque ya no existen hombres verdaderos. Las autoras se indignan de que haya familias enteras mantenidas por mujeres y que por consiguiente ya no se haga la diferencia entre el hombre y la mujer establecida por Dios en el Corán (C 4:34): "Los hombres están a cargo de las mujeres debido a la preferencia que Allah ha tenido con ellos, y deben mantenerlas con sus bienes. [...]."

Las mujeres de la Compañía al-Jansa' concluyen por lo tanto que "si los hombres fueran hombres, las mujeres podrían ser mujeres." 32 Como veremos en el último párrafo, esta argumentación es una de las líneas claves de reclutamiento para extremistas. A pesar de la desigualdad entre los sexos en una visión del mundo que concibe a la mujer como creada de una costilla del hombre y también para él, las islamistas insisten en sus derechos divinamente asignados. La así percibida "violación" de estos derechos puede haber sido uno de los grandes fomentadores de la migración de mujeres al El tanto de Arabia Saudí como de Europa.

El panfleto de al-Jansa' exige que las mujeres adquieran el saber que la religión demanda de ellas y celebra el papel de la madre como fundamento de la sociedad islámica ideal. El modelo de sociedad occidental, en el que la mujer está forzada a trabajar, no tiene fundamento en el islam, opinan las hermanas. Alegan además que es obvio que Dios no quiere un modelo así porque ni siquiera en "occidente" funciona: "estos Estados han llegado incluso a pagar a las mujeres para que se queden en casa con sus hijos y acepten por fin su rol natural de amas de casa" (Winter, 2015, p. 19).

A pesar de su rol fundamental en el hogar, las mujeres de al-Jansa' permiten a la madre y al ama de casa salir en situaciones excepcionales. Cuando los hombres en la yihad ya no consiguen proteger al país, solos contra el enemigo, y un imam importante emite una fetua que lo establece, las mujeres deben participar en la lucha armada. Esto contradice parcialmente al artículo publicado en el Dabiq que insiste que la verdadera yihad de la mujer se lleva a cabo sin luchar. ${ }^{33}$ Como veremos en el párrafo siguiente, existe una gran discrepancia en el mundo yihadista en torno al papel de la mujer en la guerra contra los infieles. Esta falta de consenso se replicó en el seno del El.

Las autoras de la compañía de mujeres también permiten a las mujeres abandonar sus casas para estudiar su religión. Además, las médicas y profesoras pueden dirigirse a sus puestos de trabajo

\footnotetext{
${ }^{31}$ Ibíd., p. 9.

32 Ibíd.

${ }^{33}$ Umm Sumayyah al-Muhajirah (dhul al-qa'da 1436 (agosto o septiembre de 2015)): "To Our Sisters: A Jihad without Fighting", Dabiq, From the Battle of al-Ahzab to the War of Coalitions, número 11, pp. 40-45.
} 
siguiendo las reglas de la sharía (que en el caso del El implica no caminar sola) sin compañía de una mujer o del guardián masculino e ir tapada con un niqab.

Esa actitud es muy diferente de la de los talibanes en los años noventa, que practicaron un lento genericidio de mujeres por no dejarlas trabajar incluso si no tenían hombre alguno que las alimentara. Tampoco les estaba permitido estudiar aunque al mismo tiempo se exigía que las mujeres fueran tratadas exclusivamente por médicas y enfermeras de su mismo sexo. Al igual que en su posición frente al mantenimiento y desarrollo de la administración pública, en asuntos de mujeres, los extremistas del El demostraron que llevaban adelante un modelo de sociedad bastante pragmático a pesar de su ideología extremista. No obstante, el plano de enseñanza para las mujeres jóvenes que propone al-Jansa' se acaba a los 15 años y sólo abarca asuntos religiosos y del hogar. El manifiesto también menciona que las jóvenes se pueden casar a los nueve pero que lo harán en su mayoría a los 16 o 17 años. Al mismo tiempo, el panfleto celebra los logros del EI por haber conseguido imponer la segregación de sexos tanto en las escuelas como en las universidades.

Las autoras de la Compañía de al-Jansa' no se olvidan de la mujer trabajadora que, no obstante, sólo debe ejercer una profesión por necesidad o servir a fines superiores de la comunidad. Trabajar para alimentar a la familia es cosa de hombres. La mujer por su parte no debe en ningún caso dejar de lado a su familia y a sus hijos. Cinco requisitos se mencionan por consiguiente para que el trabajo de una mujer sea posible en el seno del El: Primero, la mujer tiene que tener un trabajo posible de realizar por alguien de su sexo. Segundo, la mujer debe trabajar sólo tres días por semana durante pocas horas para también poder atender las necesidades del hogar. Tercero, la mujer tiene que tener la posibilidad de recibir una baja por necesidades de los niños (enfermedad, por ejemplo). Cuarto, la mujer tiene que obtener dos años de baja por maternidad. Y quinto, debe tener acceso a una guardería para los niños en el puesto de trabajo (Winter, 2015, p. 25). Así que también en lo que corresponde a las necesidades de la mujer trabajadora, las mujeres de la Compañía al-Jansa' tienen ideas muy concretas y directamente relacionadas con el mundo actual.

En la segunda parte del panfleto, las autoras describen unos ejemplos de las provincias que el El supuestamente liberó "del colonialismo y de la opresión de los nusayríes (alawíes)" (Winter, 2015, p. 27). Como un gran logro conciben las autoras que el cuerpo de la mujer sea respetado en público gracias al velo integral que lo protege de las miradas de hombres desconocidos. Esta nueva situación del velo integral obligatorio para todas pretende cumplir un sueño de muchas mujeres que lo usan tanto en las sociedades árabes como en las europeas, ya que muchas sienten ser acosadas por el hecho de andar tapadas, como veremos más adelante. Las autoras de al-Jansa' mencionan además que toda ropa "reveladora" para mujeres ha sido confiscada. Este punto es importante cuando se piensa en el hecho de que el texto fue muy probablemente redactado por $y$ para mujeres saudíes. ${ }^{34}$ Las sociedades árabes del golfo exigen de sus mujeres ir tapadas en público y vestirse de forma muy atractiva para sus maridos en privado. Con la desaparición completa de la ropa "reveladora", esta exigencia desaparece. Lo que se presenta es una sociedad

\footnotetext{
${ }^{34}$ Ya existía una revista llamada al-Jansa' en 2003 de la rama saudí de Al Qaida.
} 
"liberada" de toda provocación sexual donde mujeres y hombres pueden servir a su Dios y nada más.

Entre lo que las autoras de la Compañía al-Jansa' consideran como logros del El, el texto enumera también la mejora de la administración pública en Siria, donde las mujeres presuntamente tienen libre acceso a los tribunales de la sharía para poder arreglar asuntos de su interés como casamientos y divorcios mucho más rápido. Con ello hacen referencia a la corrupción y a la demora temporal de procedimientos jurídico-administrativos en Siria y en Iraq. A los ojos de los partidarios de las políticas islamistas, esta situación poco satisfactoria para el ciudadano común y corriente tiene que mejorar de inmediato al imponer la justicia de Dios porque supone la introducción de una justicia pura y alejada de la maldad de los hombres.

Otro punto importante para la misión de las extremistas del El es la nota acerca de que las mujeres cristianas pueden fácilmente convertirse al islam en el El sin ser molestadas. Las mujeres de la Compañía al-Jansa' aluden con ello a la crítica situación de los conversos en el seno de las sociedades árabes. Obviamente no mencionan que para las musulmanas es imposible convertirse a otro credo en su nuevo constructo político sin pagarlo con la muerte. No obstante, tienen razón al aludir al hecho de que las cristianas que quieren convertirse al islam en Siria y en Iraq son expulsadas de sus comunidades. En Egipto las historias sobre mujeres cristianas que supuestamente se convierten al islam y son encerradas por sus antiguos correligionarios son un componente importante de muchas leyendas urbanas que pueden llevar a levantamientos armados de pueblos enteros. ${ }^{35}$

Un último punto que las activistas del panfleto de al-Jansa' mencionan es la mejora en la lucha contra la pobreza de la mujer. Para ello el El estableció oficinas del zaka (de donaciones para los pobres) que les asignan pagos. Además, las mujeres pueden trabajar en los mercados. Esta última nota sorprende porque no parece novedosa. Sin embargo, al igual que el mantenimiento de la educación, demuestra que los pensadores del El atribuyen a las mujeres un papel pragmático en la sociedad incluso en casos que no corresponden a su ideal del ama de casa.

El texto sobre las mujeres en el El no deja de mencionar que en el nuevo califato todos las musulmanas y musulmanes son iguales y que el El no discrimina ni a los autóctonos ni a los inmigrados según su etnia, raza, nacionalidad, familia o tribu de origen. Este ideal de una comunidad de creyentes sin discriminación alguna es un viejo sueño de muchos filósofos musulmanes tanto liberales como extremistas. En muchas sociedades árabes contemporáneas parece una visión bastante utópica ya que la discriminación según los criterios mencionados parece endémica: Los miembros de las diversas tribus sólo se casan entre ellos, los lazos familiares determinan la carrera profesional y los más obscuros o negros de piel se ven discriminados por ser "feos". Tales actitudes son consideradas con razón como poco islámicas.

Las mujeres de la Compañía al-Jansa' celebraron su popularidad en los medios de comunicación de habla inglesa y francesa en un texto intitulado La rabia de los enemigos ${ }^{36}$. Las autoras comentan que su texto no sólo fue mencionado en los medios más importantes del mundo sino también traducido al inglés y al francés. Concluyen afirmando que las plumas de las hermanas cortan como los sables de los muyahidines. Si se contrasta esta actitud con la nota inicial que reduce el tratado

\footnotetext{
${ }^{35}$ El caso de Camelia Shehata es un buen ejemplo (RAYMOND, Ibrahim, 2011).

${ }^{36}$ Sariyat al-Jansa' al-i'lamiyya (12 de marzo de 2015): Taghith al-'Ada', justpaste.it.
} 
a un texto para mujeres sin relevancia oficial estatal, tales comentarios resultan sorprendentes. ¿Será que las hermanas quieren mostrar a los observadores externos que no son seres pobres y oprimidos sin poderes de actuación propia? ¿O acaso intentan demostrar a sus propios hombres su importancia para el califato?

\section{La mujer y la yihad}

Los pensadores que defienden la lucha armada por la fe como tarea activa e importante de la comunidad musulmana desde Ibn Taymiyya ${ }^{37}$ hasta el día de hoy están convencidos que la yihad es fard al-'ayn. Esto significa que se trata de una obligación de Dios que forma parte substancial de la religión. Otras obligaciones de la misma índole se encuentran entre los cinco pilares del islam: las cinco oraciones diarias, el ayuno durante el mes del ramadán y la donación para los pobres. Como tales obligaciones representan un sine qua non para hombres y mujeres musulmanes, los ideólogos de la yihad deliberan sobre el papel que deben tener sus compañeras en la lucha armada por la religión. Hay varias conclusiones en esa materia. En lo que corresponde a la red terrorista internacional Al Qaida, sus líderes y seguidores discuten este asunto desde el año 2005 con bastante pasión.

No sorprende que Abu Mus'ab az-Zarqawi ${ }^{38}$ haya hablado a favor de una participación activa de las mujeres en la yihad en Iraq. El 9 de noviembre de 2005 mandó a una mujer a llevar a cabo un atentado suicida en la capital de su país de origen, Amman. A continuación, en Iraq también se acumularon los atentados de este tipo perpetrados por mujeres.

Entre los años 2007 y 2008 el jefe de Al Qaida, Dr. Ayman az-Zawahiri, se pronunció durante su campaña de relaciones públicas sobre el tema de la participación femenina en la yihad. ${ }^{39} \mathrm{El}$ cirujano egipcio dijo entonces que Al Qaida no tenía mujeres en sus filas y que las esposas de los luchadores tenían la obligación de cuidar de sus maridos y sus familias. Con ello enfadó a una buena parte de sus discípulas. Parece que para el mes de diciembre 2009 Zawahiri ya había reconocido su error, pues apareció un texto firmado por su mujer Umayma Hasan dirigido a sus "hermanas musulmanas".

La primera dama de Al Qaida empieza su carta con una cita de Abdullah Azzam, en la que este afirma que la yihad era fard al- 'ayn para todos los musulmanes, hombres y mujeres desde la caída del al-Ándalus. No obstante, la labor más importante de las mujeres en este asunto sería apoyar a los hombres, concluye Umayma. Con ello confirma parcialmente la actitud negativa de su marido hacia la cuestión de una participación activa de las mujeres en las luchas armadas por la fe. Dice al respecto que es muy difícil para una mujer combatir en el frente porque siempre necesita un

\footnotetext{
${ }^{37}$ Pensador musulmán polémico de los siglos XVIII y XIV que sirve de modelo a muchas escuelas extremistas.

${ }^{38}$ Abu Mus'ab az-Zarqawi (5 de julio de 2005): Does the Religion Wane While I am Still Alive, mensaje de audio. Es importante recordar que fue una de sus hermanas quien contribuyó esencialmente al desarrollo de sus convicciones extremistas personales.

${ }^{39}$ Después de una serie de atentados fallidos y con muchos muertos musulmanes, el apoyo popular (sobre todo en Arabia Saudí) por el grupo empezó a disminuir y, por consiguiente, una campaña publicitaria debía mejorar la situación. El máximo líder contestó preguntas de sus seguidores en foros yihadistas en internet.
} 
mahram, un guardián que la proteja. Sin embargo, la esposa de Zawahiri justifica los atentados suicidas de "las hermanas" en Palestina, Chechenia e Iraq y subraya que tales operaciones fueron llevadas a cabo como apoyo directo a los hombres. Por consiguiente, las mujeres actuaron no por iniciativa propia ni por una actitud ofensiva sino solamente como asistentes de los luchadores masculinos.

Umayma Hasan habla de muhayirat (mujeres migrantes al frente del combate) y murabitat (mujeres que residen con sus hombres en el frente del combate) y no de muyahidat o mujeres combatientes. Con ello queda también lingüísticamente claro que no considera la lucha de la mujer en la yihad, sino el hacerle compañía al hombre que lucha como el rol femenino en esta obligación divina. Como modelos históricos para las mujeres luchadoras menciona a Sayida Safiya, que según ella mató a un judío con un palo mientras los hombres estaban luchando y demostró con ello que la violencia de la mujer contra el enemigo era lícita para su autodefensa. El segundo ejemplo que da la esposa de Zawahiri es el de Umm 'Imara, quien defendió al profeta Muhammad durante los combates, fue herida y perdió un brazo. Pero Umayma Hasan subraya que el modelo más importante a seguir es Jadiya, la primera mujer del Profeta Muhammad, que le apoyó fuera del campo de batalla.

La primera dama de Al Qaida se dirige a tres grupos de hermanas. Primero a las mujeres en el ard ar-ribat, cuyos maridos e hijos están luchando por el islam y a quienes deben apoyar. Luego se dirige a las mujeres que tienen maridos que se encuentran encarcelados en los calabozos de los tiranos y finalmente se dirige a todas las mujeres del mundo y hace un llamamiento por el velo correcto. Concluye que la campaña contra el velo es el combate más duro entre el islam y los infieles. En su opinión primero los infieles criminales intentan obligar a las mujeres musulmanas a quitarse el velo para empujarlas luego a abandonar su fe. Por consiguiente, llama a las mujeres a educar a sus hijos para la yihad y animar a sus maridos, hermanos e hijos a participar en la lucha armada. Otro rol en la yihad que debe cumplir la mujer será, de acuerdo con ella, el proselitismo $(d a w a)^{40}$ y la recaudación de dinero para los combatientes y para apoyar a las familias de los presos y de los mártires. Umayma Hasan concluye con las palabras siguientes:

"Confirmo para mis hermanas musulmanas en todo el mundo que las mujeres juegan un papel importante en el activismo islámico. Las mujeres son hermanas de los hombres, eso quiere decir que tienen que trabajar a su lado para defender su religión y su país. La mujer lo hace con su alma y si no puede hacerlo, con su dinero, y si no puede hacerlo, como misionera de su religión y con las mujeres musulmanas en las mezquitas, escuelas, instituciones y casas. Y si tampoco puede hacer eso, entonces en internet. Debe escribir su misión, publicarla y diseminarla entre los muyahidines. Si Dios quiere encontrará ojos y corazones abiertos para ello. Deseo, mi hermana, que no te canses o te aburras de defender nuestra religión de la manera que puedas" 41

La actitud frente a la posibilidad de una participación directa de la mujer en los combates de la guerra no está del todo clara en los escritos del El. En lo que se puede considerar como

\footnotetext{
${ }^{40}$ El significado más básico de da'wa en árabe es "invitación” que en términos religiosos también se entiende como “invitación al bien" o "fomentación del bien". No obstante, los activistas del extremismo la entienden claramente como obra de proselitismo que para ellos es equiparable con la predicación del bien.

${ }^{41}$ Umayma Hasan Ahmad Muhammad Hasan (16 de enero de 2010): risala ila al-ijwat al-muslimat, minbar at-tawhid wa-l-yihad, p. 4. La carta fue publicada un mes después de su aparición en distintos foros islamistas en la página web de Abu Muhammad al-Maqdisi donde seguía hasta el mes de mayo 2018.
} 
publicación oficial, las representantes se posicionan a favor de "una yihad sin luchar", como lo indica ya el título de un artículo de Dabiq que fue publicado entre agosto y septiembre de $2015 .{ }^{42}$ Umm Sumayya al-Muhajirah empieza por decir que "cuando Allah hizo la yihad por su causa obligatoria para sus esclavos hombres y le asignó una recompensa que no se puede encontrar en otras obligaciones, algunas mujeres tuvieron envidia y celos." 43 Por eso intenta demostrar a sus hermanas lo que significa para ellas hacer la yihad:

“De hecho estás en la yihad cuando esperas con paciencia a tu marido con la expectativa de una remuneración [en el más allá] y [cuando] haces du ' $a$ ' [suplicas a Dios] por él y por los que están con él para que lleguen a la victoria y la consolidación. Estás en la yihad cuando le sigues fiel en su ausencia. Estás en la yihad cuando enseñas a sus hijos la diferencia entre la verdad y lo falso, entre lo bueno y lo malo." 44

Con la ausencia del marido se refiere al tiempo durante el cual el hombre participa en la yihad, así como a su condición de preso en las cárceles del enemigo. Está claro que con estos argumentos Umm Sumayya al-Muhajirah defiende una posición semejante a la de Umayma Hasan.

Además, la representante del El hace una alusión corta a los requisitos de la madre yihadista, que tiene que ser "maestra de las generaciones de pequeños leones y también su productora." 45 La posición de la madre reducida a una máquina reproductora de combatientes varones no podría ser más explícita que en este artículo.

Para definir lo que debe ser la umma y el papel de la mujer en ella, la yihadista se sirve además de una referencia bien conocida de la teoría política occidental que fue usada en varias ocasiones para la constitución ideológica de regímenes dictatoriales: la analogía orgánica. Para Umm Sumayya al-Muhajira, "la umma es un cuerpo con muchos miembros y el más efectivo [de ellos] para criar una generación de musulmanes es la madre alimentadora." 46 La madre tiene que enseñar a sus hijos 'aqida (fe), kufr bi-t-taghut (la apostasía del tirano), ${ }^{47}$ fiqh (la jurisprudencia) de la yihad y la admiración por el único Dios. Además, tiene que leerle a sus hijos la biografía del Profeta y mashari' al-ashwaq ila masari' al-'ushaq ${ }^{48}$ de Ibn Nahhas ${ }^{49}$, el llamado Libro de la yihad. La autora del Dabiq asegura a la madre de los futuros combatientes por la fe que en el nuevo

\footnotetext{
${ }^{4}$ Umm Sumayyah al-Muhajirah (dhul al-qa'dah 1436 (agosto o septiembre de 2015)): "To Our Sisters: Jihad without Fighting", Dabiq, From the Battle of al-Ahzab to the War of Coalitions, número 11, pp. 40-45.

${ }^{43}$ Ibíd., p. 41.

${ }^{44}$ Ibíd., p. 41.

45 Ibíd., p. 44.

46 Ibíd.

47 La "apostasía del tirano" se refiere al deber de la comunidad de matar a un líder político considerado como apóstata. Esta enseñanza es importante porque tradicionalmente la teoría política sunní prefiere mantener a un tirano como líder para evitar la anarquía (Sivan, 1985).

${ }^{48}$ La traducción literaria sería "Proyectos pasionarios para el combatiente de los enamorados" y se inscribe en la tradición árabe de formular títulos con rima y con una repetición de palabras con un sonido similar.

49 Abu Zakariya al-Dimashqi al-Dumyati es un pensador del temprano siglo XV. Huyó de Damasco a Egipto de la invasión de los mongoles y murió combatiendo a los romanos. Su biografía se encuentra sobre todo en páginas web de grupos extremistas.
}

REIM № 24 (junio 2018)

ISSN: $1887-4460$ 
califato hay campos de entrenamiento y guarderías para sus hijos e insiste en que primero debe trasmitirse el saber y luego el uso de las armas.

Algo más ofensiva en su vocación por lucha directa y más detallada en sus instrucciones para la madre del combatiente fue la yihadista que redactó un manifiesto en el mes de enero del año 2012 firmando con la abreviación anónima "Sister Al...". Su texto de 17 páginas fue publicado en inglés y subido a la plataforma archive.org el 21 de enero por alguien que usa el nombre de Ihann. El texto empieza con la cita del Corán (C 9:71):

"Los creyentes y las creyentes son aliados unos de otros, ordenan el bien y prohíben el mal, cumplen con la oración prescrita, pagan el zakât y obedecen a Allah y a Su Mensajero. Allah tendrá misericordia de ellos; y Él es Allah, Poderoso, Sabio."50

La autora quiere subrayar que los hombres y las mujeres son aliados los unos de los otros y por ello añade a la cita coránica el hadiz siguiente:

"Quien sea de vosotros que note un munkar (una violación de la orden de Dios), debe corregirlo con sus propias manos, si no puede hacerlo, que lo prohíba con su lengua, si no lo puede que lo considere como mínimo mal en su corazón. Este es el nivel más bajo de la fe." 51

Sister Al concluye que eso quiere decir que las mujeres y los hombres tienen que ser aliados incluso en la yihad. La violación más fuerte de la orden de Dios la detecta en la incredulidad y en el politeísmo. La mejor corrección para ambos es, según Sister Al, la yihad. Además, como en el momento actual los países de los musulmanes están ocupados por los infieles, la autora opina que la yihad debe ser considerada fard al-'ayn. Para cumplir con una obligación de este nivel, la mujer no necesita ni siquiera el consentimiento de su marido o de su mahram, concluye Sister Al.

También considera que el papel de la hermana en la yihad no es solamente de apoyo al hombre fuera del campo de batalla. Para justificar la participación directa y activa de las mujeres en las filas de los combatientes de la yihad, Sister Al nombra a sus modelos de la historia islámica. Empieza con el ejemplo de Nusayba bint Ka'b, llamada Umm 'Imara, a quien ya había mencionado la mujer de Zawahiri en su carta a las hermanas musulmanas. No obstante, Sister Al hace hincapié en la fuerza de la mujer que lucha y no en la situación excepcional en la que se tuvo que defender porque los hombres estaban ausentes y luchando en otra parte. Lo que es más sorprendente es su cita de un ejemplo que data de la historia más reciente y que no está relacionado directamente con los salaf, las primeras generaciones de los musulmanes que son venerados como ejemplares representantes de la religión. Se trata de la mujer de Mahmud Qutus, mejor conocido por el nombre de Saif ad-Din Qutuz, el Sultán de los mamelucos en Egipto que venció a los mongoles durante su corto reinado. Las crónicas islámicas narran que durante estas guerras la mujer del sultán murió mientras luchaba a su lado en el campo de batalla (Maalouf, 1991). Esta mujer del siglo XIII que se llamaba Yulanar según algunas fuentes parece un ejemplo de combatiente a caballo en el frente mucho menos radiante que Aisha, la mujer del Profeta. Desafortunadamente, la Batalla del Camello del año 656 en la que participó Aisha fue la primera en la que musulmanes

\footnotetext{
50 Vid.: referencia para las citas coránicas más arriba.

${ }^{51}$ Hadiz de Muslim número 34, Abu Sa id al-Judri.
} 
lucharon contra otros musulmanes. Por esta razón, no suele servir como ejemplo digno de la historia militar islámica.

Aparte de la lucha en la guerra, Sister Al también nombra la posibilidad de la hermana musulmana de apoyar a los combatientes organizando el suministro de víveres y animándolos en el frente. Otros servicios que las mujeres pueden proveer en el frente de batalla serían los primeros auxilios y la vigilancia. Sister Al recomienda a la mujer yihadista prepararse mentalmente mirando imágenes sangrientas, siguiendo el ejemplo de Safiyya Bint Abdul Muttalib, que quiso ver el cuerpo mutilado de su hermano Hamza y que se mantuvo firme mientras lo miraba. Esta recomendación parece coherente en el contexto de las imágenes sangrientas difundidas por el El. Parece que no sirven solamente para probar su superioridad en el combate contra los "enemigos infieles", sino también para endurecer a sus seguidores.

A pesar de sus recomendaciones para las hermanas que participan activamente en los combates, Sister Al también considera que el papel más importante de la mujer en la yihad es el de ser la madre de los futuros luchadores. Urge a las madres de los musulmanes a educar a sus hijos desde pequeños para la yihad. Sister Al precisa también el contenido de una educación de este estilo: los niños tienen que aprender a distinguir los amigos de los enemigos y pelear sólo con los últimos. Además, se les tiene que enseñar a tirar con armas de juguete. Solamente debe permitírseles ver programas de televisión que eduquen en la religión o glorifiquen la yihad. A los niños también se les prescribe entrenamiento físico. Como historias de antes de dormir se les aconseja a las madres leer cuentos de los muyahidines, de los combatientes por la religión. Sister Al insiste en que las madres tienen que aprender ellas mismas como mínimo autodefensa y tiro para estar listas en cuanto empiece la yihad. Para su educación en asuntos de la yihad, Sister Al recomienda a sus seguidoras leer los escritos de Abdullah Azzam, el cofundador de Al Qaida.

Aparte de la educación, Sister Al empuja a sus hermanas a animar a los hombres de sus familias a participar en la yihad. Les dice que no deben en absoluto intentar impedir que los hombres vayan a luchar por su fe porque eso sería un pecado. Otros servicios que se pueden prestar para la yihad si no se participa directamente en los campos de batalla son la recaudación de dinero para el equipamiento de un combatiente (que equivale a la participación en la lucha) y el proselitismo. ${ }^{52}$

El texto no indica a qué grupo pertenece Sister Al. En los documentos que analizamos más arriba y que tienen un sello claro del El, se le asigna a la mujer el papel de madre, esposa y educadora en el nuevo califato islámico. La hiyra al califato se declara como obligatoria para mujeres incluso sin guardián. En la yihad, las mujeres tienen que apoyar a los hombres y tienen una gran responsabilidad a la hora de recaudar fondos y reclutar seguidores. En lo que corresponde a la posibilidad de tomar parte en el combate como luchadora, existen testimonios de mujeres que fueron educadas a llevar armas en el El. No obstante, se considera que eso sirve sobre todo para

\footnotetext{
52 El panfleto fue publicado en enero de 2012 en la plataforma archive.org. La prensa inglesa solamente lo notó tres años más tarde. El 31 de diciembre de 2014 el Daily Mail Online escribió sobre una presunta guía del El acerca de How to Raise a Jihadi-Baby [...] (Pleasance, 2014). Un día más tarde el Independent se enfadó en su título: Isis-Booklet Issues Guidelines to Mothers on How to Raise Jihadi Babys (Withnall, 2015). ISIS no existía bajo este nombre en 2012, por lo tanto, el título del Independent es anacrónico. Además, no se menciona la pertenencia de la autora a ningún determinado grupo islamista en el texto.
} 
poder defenderse y, en última instancia, apoyar a los hombres cuando ya no consigan defender al califato solos.

A pesar de su título militar, la Compañía al-Jansa' operó sobre todo como unidad de propaganda y también como policía de la virtud que iba corrigiendo a las mujeres por las calles y revisaba a las mujeres tapadas verificando su identidad. En lo que corresponde a las fuentes que muestran una implicación más activa en el frente, no sabemos a qué grupo pertenece Sister Al. En un video de Alepo podemos ver el entrenamiento de un contingente de mujeres luchadoras bajo el título annisa' tamkin, el empoderamiento de mujeres. ${ }^{53}$ Ello muestra que siguen existiendo diferentes opiniones en el mundo yihadista acerca de la implicación de las mujeres en la guerra.

\section{Conclusiones}

Los islamistas de toda índole, tanto los que se suelen oponer al uso de la violencia -como los hermanos musulmanes o Hizb at-Tahrir-como los salafistas quietistas y los yihadistas violentos, predican un discurso de victimización en el que describen a los musulmanes como un grupo perseguido y oprimido por los infieles y los tiranos (calificados de apóstatas) aliados con ellos. Dependiendo de la ocasión, esta historia se puede hacer más o menos extensa. Puede empezarse con las primeras guerras de expansión del islam en los siglos VII y VIII o bien con la caída del Califato de Córdoba y la Reconquista.

Por consiguiente, los islamistas quieren fundar un califato para que los musulmanes puedan vivir en paz. No obstante, dependiendo de la escuela de pensamiento del islamismo, este Estado ideal no es solamente necesario para proteger a los musulmanes de la opresión, sino para restaurar el califato que fue abolido en 1924 por Turquía, lo cual se puede considerar como un mandamiento de Dios. Este califato debe incluir como mínimo todas las tierras que estuvieron bajo mandato musulmán en el pasado. Eso abarca, por ejemplo, a la Península Ibérica, Sicilia, los Balcanes y el norte del Cáucaso. Para grupos imperialistas como el El, el dominio de su califato debe extenderse al mundo entero.

Los islamistas se consideran oprimidos -con o sin razón- y formulan esta percepción en una analogía de guerra perpetua. Para ello se refieren a guerras de la historia reciente o del mundo actual y las definen como conflictos evidentes entre la fe y los infieles. Así, interpretan las guerras de Afganistán desde 1979, el conflicto entre Israel y Palestina (desde la fundación del Estado de Israel en 1948), las guerras de Chechenia (de 1994 a 1996 y de 1999 a 2009), de Yugoslavia (de 1991 a 1999), las del Golfo (de 1990 a1991, de 2003 a 2011 y la actual) y la de Somalia (desde 1991) como ejemplos claros de guerras de religión de musulmanes contra infieles. Estos conflictos y guerras sirven además como pruebas de una conspiración de los infieles en contra de los musulmanes. Desde un punto de vista práctico, existen veteranos de estas guerras que instruyen a los jóvenes reclutas. Además, hay cuentos innombrables de mártires que murieron en estos campos de batalla que son glorificados como modelos a seguir por los islamistas.

${ }^{53}$ Nisa' at-tamkin (ca. 2013), jayr al-umma, Alepo. 
En la relativa situación de paz que puede fingir un sistema político dictatorial, los presos comunes o políticos islamistas son usados como prueba importante de la maldad de los regímenes. Desde el tratado de Zaynab al-Ghazali (ayam min hayati) ${ }^{54}$ existen múltiples tratados de hombres y mujeres, así como una amplia colección de videos sobre personas que sufrieron abusos en las cárceles en los países árabes o en las bases militares estadounidenses, como Bagram o Guantánamo. En esta situación de inseguridad constante de familias islamistas que viven siempre con un pie en la cárcel, la llamada del califato que supuestamente protege sus derechos parece seductora.

En el artículo de Dabiq sobre "la yihad sin luchar" Umm Sumayyah al-Muhajirah hace hincapié en la prisión y narra cómo el marido se alegra cuando viene su mujer de visita. Concluye que la mujer (aunque sea su derecho) no debe pedir el divorcio cuando el marido está en la cárcel. ${ }^{55}$ Con ello hace alusión a una situación tensa en la que las mujeres de los hombres sufren mucho en su ausencia (de manera emocional pero también económica). Además, con el llamado a las mujeres a no abandonar a sus maridos encarcelados por los tiranos, Umm Sumayyah al-Muhajirah nos permite suponer que tales separaciones forzosas ya han llevado a la ruptura de familias.

Pero no sólo los hombres islamistas se ven perseguidos en los Estados árabes, también las mujeres corren el riesgo de ir a prisión. En el tratado sobre la situación de la mujer en el Estado Islámico publicado por al-Jansa', las autoras mencionan que las mujeres sunnitas ya están libres y se pueden desplazar sin miedo de ser secuestradas, violadas y encarceladas por los "chiitas cruzados" (Winter, 2015, p. 27). Con ello se refieren al régimen de la mayoría chiita que tomó el poder en Iraq después de la caída de Saddam Hussein aprovechándose de la nueva situación para vengarse de sus antiguos opresores. Como el tratado se dirige sobre todo a mujeres de Arabia Saudí, las autoras escriben que hay mujeres en las cárceles del Reino que son violadas, así como las sunnitas lo fueron previamente en Iraq antes de su supuesta liberación por el El. Además, añaden que muchas hermanas saudíes siguen sin saber lo que pasó con sus maridos que desaparecieron en las cárceles. En el El esto supuestamente no ocurre. También añaden razones religiosas que sirven para descalificar al Reino de Arabia Saudí como Al as-Salul, refiriéndose con ello a un líder politeísta de la época fundadora de la religión que se había convertido al Islam, pero más tarde traicionaría al profeta Muhammad. Tratan al Estado Wahabita de hipócrita en asuntos religiosos. Las autoras de al-Jansa' escriben al respecto que Arabia Saudí se ha occidentalizado y que ya no impone la segregación de sexos en las universidades. Además, deploran el acceso de estudiantes cristianos a las mismas y de "profesores extranjeros depravados que envenenan la situación con sus pensamientos ateos." 56 Añaden que el régimen saudí abusa de las mujeres mientras que se felicita a si mismo por no dejarlas conducir. Se enfadan de que se muestre a mujeres que no están vestidas de forma modesta en la televisión. Al final, las autoras se quejan de que el Reino Saudí no apoya suficientemente a las mujeres pobres y que les impide vivir de manera digna poniéndoles innumerables obstáculos administrativos.

\footnotetext{
54 “Días de mi vida” (Al-Ghazali, 1981).

55 Umm Sumayyah al-Muhajirah (dhul al-qa'dah 1436 (agosto o septiembre de 2015)): "To Our Sisters: A Jihad without Fighting", Dabiq, From the Battle of al-Ahzab to the War of Coalitions, número 11, pp. 40-45.

${ }^{56}$ Ibíd., pp. 38-39.
}

REIM № 24 (junio 2018)

ISSN: $1887-4460$ 
El 27 de mayo de 2015 las mujeres saudíes seguían como portavoces del El y denunciaron la hipocresía de algunos teólogos importantes en su antigua patria. Después de un atentado del El en contra de lo que definen como "un templo politeísta de los rafida" (es decir, una mezquita chiita) en Qatif 57 muestran tweets de diferentes teólogos saudíes respetados que antes del atentado fomentaran la ira en contra de los chiitas y después del atentado se declararan solidarios con ellos diciendo que aquello era la obra de terroristas que comprometían la seguridad del Reino y provocarían fitna (confrontaciones violentos entre musulmanes). Las mujeres rechazan en 34 páginas la opinión de los teólogos varones y demuestran que no tienen vergüenza de llevar un combate ideológico contra hombres que, en su opinión, interpretan y viven el islam de manera equivocada. Por consiguiente, con esta actitud las mujeres se liberan y se emancipan de un régimen que las oprime sin razón. Como vemos en sus argumentos, las saudíes, portavoces femeninas del El, están dispuestas a llevar un velo integral porque lo consideran obligatorio para las musulmanas por orden divina, sin embargo, opinan que prohibirles conducir no tiene sentido. Para una mujer saudí, si seguimos estos argumentos, la migración de su patria al El puede por lo tanto efectivamente interpretarse como un movimiento emancipador.

En octubre de 2014 apareció la carta de Ahlam Nasr, una joven siria educada en Arabia Saudí que volvió a su país de origen para vivir en el El. La veinteañera se hizo famosa por ser la poetisa del califato. En su carta cuenta cómo se despidió de su madre, una profesora de fiqh, de jurisprudencia islámica, de la Universidad de Dammam en Arabia Saudí. Cuenta que su madre lloraba por detrás de la puerta de su habitación y que ella le dijo entonces que tenía que acordarse de su nacimiento y de cómo había dicho que esa hija servirá al islam. Ahlam aclaró a su madre que eso era justamente lo que iba a hacer. No olvida de mencionar que fue su madre quien la educó, le cantó y le inculcó el amor por el islam, la yihad, el califato y el gobierno islámico (hukm). Ahlam Nasr concluye que aquellas son las obligaciones compartidas por ellas. Su carta continúa con un relato sobre el El, donde los musulmanes viven felizmente y disfrutan de una administración pública que funciona. ${ }^{58}$

Hasta su casamiento con el yihadista austríaco de origen marroquí Muhammad Mahmoud, cuyo nombre de guerra es Abu Usama al-Gharbi (Creswell y Haykel, 2014), Ahlam estaba muy activa en su blog donde publicó poemas, artículos, una caricatura, dibujos y anuncios sobre la ley islámica. 59 No sorprende que el primer poema que aparece en su blog es una oda a los presos: fa-ruhi talliqun wa-anhum bayd ("Mi alma es libre mientras que ellos están lejos") es un poema que se refiere a las penas que pasan los presos en las cárceles. ${ }^{60}$ También escribió un poema llamando a la liberación de Hayla al-Qasir, una mujer saudí que está encarcelada en su país por haber recaudado mucho dinero para Al Qaida en la Península Arábiga. ${ }^{61}$ El El lo convirtió en un nashid (un himno (religioso) cantado por hombres sin acompañamiento musical).

La Compañía de al-Jansa' no sólo celebra a Hayla al-Qasir como una heroína y presa política, sino también a Aafia Sidiqqi, una mujer de origen pakistaní que fue casada con 'Ammar al-Baluchi, un

\footnotetext{
57 Sariyat al-Jansa' al-i'lamiyya (27 de mayo de 2015): Al-qul al-hasif fi tafyir hussayniyya al-qatif, justpast.it. El atentado ocurrió el 22 de mayo de 2015.

${ }^{58}$ Elwatannews (15 de octubre de 2014): Wa-akhiran rabbna katab as-samahan, qissa yadida li-l-yihad al-5 nuyum" (y por último Dios dio su permiso, nueva historia sobre la yihad de cinco estrellas).

${ }^{59}$ https://ahlam-alnasr.blogspot.de/ [consulta: 4 de enero de 2018].

60 Ibíd.

${ }^{61}$ Ibíd.
} 
sobrino de Jalid Sheikh Muhammad, el cabecilla del ataque del 11 de septiembre. Fue detenida en Afganistán en 2008 y extraditada a Estados Unidos por haber atacado a un soldado americano durante el interrogatorio en suelo afgano. En 2010 se le juzgó por un cúmulo de delitos comunes que no tienen nada que ver con terrorismo y fue condenada a 89 años de cárcel. No solamente los islamistas yihadistas consideran que la doctora en neurología fue juzgada injustamente, sino que el caso causó una ruptura en las relaciones diplomáticas entre los Estados Unidos y Paquistán. Uno de los videos de al-Jansa' la muestra durante una ponencia sobre los derechos de la mujer musulmana que dio en Houston en los años noventa. Las editoras del El cortaron parte de la conferencia camuflando el rostro de Aafia dado que en su Estado está prohibido mostrar las caras de las musulmanas libres. Se trata de una serie que lanzaron las activistas de al-Jansa' en defensa de las musulmanas en las cárceles sobre todo en los Estados árabes. Por su situación de prisionera del infiel enemigo americano, Aafia tiene un valor igual a sus compañeros en Guantánamo. El video muestra una corta toma de posición de Abu Yahya el-Libi, que fue un alto cargo de Al Qaida en la Península Arábiga y pretende haber visto a Aafia en la cárcel de la base aérea de Bagram. Aquello es para añadir leña a las teorías de la conspiración mundial contra los musulmanes, que supuestamente llevan a cabo los infieles americanos.

Por consiguiente, el El les promete a las mujeres musulmanas la liberación de la persecución por razones religiosas por las que algunas de ellas supuestamente se encuentran en las cárceles árabes y americanas. Además, el El declara que la migración a su nuevo califato es obligatoria para todos los musulmanes y las musulmanas, los cuales no deben permanecer (si no es por fuerza mayor o para luchar contra los infieles) en las tierras de los infieles (dar al-harb, casa de la guerra). Por lo tanto, si una musulmana decide no viajar al El a pesar de tener la posibilidad, se le considera como apóstata, digna de ser ejecutada.

Por su parte, Umm Sumayyah al-Muhajirah anima no solamente a las mujeres a emigrar al califato sin mahram desde países lejanos, sino también incita a las mujeres de las milicias sirias a regresar al islam correcto. Ella explica que ya solamente existen dos campos en Siria, el del iman (de la fe) y el del kufr. Está convencida de que los que luchan por Dios no pueden ser heridos por los que luchan por otros conceptos como el Estado secular, el patriotismo, el nacionalismo, la democracia o el socialismo. Concluye que aquellos son todos fines kufri a los que Allah no les confiere ninguna autoridad y que ellos solamente llevarán desgracia en la dunya (la vida en este mundo) y un fuego devastador en el más allá para sus seguidores. ${ }^{62}$ Se dirige a las mujeres de los soldados sahwah. Así designa el El a todas las milicias que luchan en su contra. Con ello se refiere al movimiento de las tribus iraquíes que se aliaron con los estadounidenses para vencer a la primera encarnación del El que aún se llamaba Al Qaida en el País de los dos Ríos (o sea Iraq), bajo el mando de Abu Mus'ab az-Zarqawi. Umm Sumayyah al-Muhajirah narra como nota introductoria la historia de Zaynab, la hija del profeta Muhammad, que estaba casada con Abul-As Ibn ar-Rabi. Cuando Muhammad recibió la revelación, Jadiya y sus hijas se convirtieron. Él, no obstante, permaneció firme en su politeísmo. Zaynab terminó por separarse de su marido por amor a Dios. Por ello Umm Sumayyah

\footnotetext{
62 Umm Sumayyah al-Muhajirah (ramadán 1436 (junio o julio de 2015)): “From Our Sisters: They Are Not Lawful Spouses for One Another", Dabiq, The Law of Allah or the Laws of Men, número 10, p. 42.
}

REIM № 24 (junio 2018)

ISSN: $1887-4460$ 
al-Muhajirah declara que es obligatorio hacer hiyra para las mujeres de los sahawat si estas no quieren ir al infierno. 63

En lo que se refiere a las mujeres fuera de las tierras islámicas, las islamistas intentan promover su visión dicotómica del mundo en los foros y blogs islámicos. En los foros en español el tono de las discusiones es todavía mucho menos agresivo de lo que se puede leer en inglés, en francés o en alemán. Un blog en alemán llamado an-niqab.de servía, antes de ser cerrado, a las mujeres que llevaban velo integral como foro para compartir sus supuestos "martirios" en la sociedad que les rodeaba. Se contaban historias de miradas feas, de insultos y también de la incomprensión con la que se topaban cuando iban a algún ministerio por asuntos administrativos y se negaban de hablar con funcionarios del sexo opuesto. Ahora existe otro blog alemán de este tipo que se llama nosoprimís, ${ }^{64}$ cuyo nombre ya resume el rumbo que toman los artículos. En castellano hay un testimonio de una mexicana munaqaba (que lleva un velo integral) en youtube que menciona que se siente discriminada por ir tapada a la universidad. ${ }^{65}$ No obstante, subraya que, aunque haya perdido todos los amigos, ha ganado "hermanas y hermanos por la causa de Allah". ${ }^{66}$ Con ello muestra la importancia que los islamistas dan a su comunidad, la cual distingue claramente entre los que forman parte de ella y los que les son hostiles -es decir, el principio de al-wala' wa-l-bara'. La lucha por el velo, que distingue a las musulmanas de las infieles, es, como ya vimos, considerada como una batalla importante a ganar por la mujer de Zawahiri.

En castellano, lo que además llama la atención en los relatos de las conversas es que se consideran "regresadas al islam",67 una nota que no se suele hacer en inglés, alemán o francés. Esta referencia podría contribuir al discurso irredentista en torno a la reconquista del al-Ándalus que promueven los islamistas.

Además, las mujeres del El reprochan a los hombres el no ser hombres de verdad. Esta es una acusación que se les hace a los hombres musulmanes por sus correligionarias en diferentes foros. Una mujer ecuatoriana conversa da consejos sobre cómo encontrar a un marido en su blog. Dice que el problema es incluso más grande para "aquellas musulmanas que practican el Islam en países donde los musulmanes somos aún una minoría." ${ }^{8}$ Con eso da por hecho que el islam está

\footnotetext{
${ }^{63}$ Se dirige de modo explícito contra el frente de Yualni y contra la Liwa' at-Tawhid en Alepo.

64 ihr-unterdrückt-uns.jimdo.de [consulta: 3 de enero de 2018].

65 Mujeres Musulmanas (11 de febrero de 2017): "Musulmana cuenta su experiencia con el niqab en México", Youtube, https://www.youtube.com/watch?v=wuWoS1ADH1k, minuto 6:02 [consulta: 12 de enero de 2018].

66 Ibíd., minuto 3:18.

${ }^{67}$ Ejemplos: Mañana domingo después del salat asr (16:00h) comenzaremos el curso para mujeres regresadas al islam en la mezquita Al-Furqan de Bilbao inshallah, http://wwwislamgurea.blogspot.de/2013/11/inicio-del-curso-paramujeres.html [consulta: 5 de enero de 2018].

Más latinas regresan al Islam, https://plataformaparamusulmanes.wordpress.com/2016/08/15/mas-latinas-regresanal-islam/ [consulta: 7 de enero de 2018]. Existe una explicación del uso de "regresar al islam" en el blog Mis apuntes de islam en un artículo con el título "por qué decimos 'regresar al islam'” que hace referencia a la idea de que todos los seres humanos nacen musulmanes y sólo se convierten a otras religiones a posteriori mediante ritos específicos. http://misapuntesdeislam.blogspot.de/2014/07/por-que-decimos-regresar-al-islam.html_[consulta: 7 de enero de 2018].

68 Una musulmana ecuatoriana da consejos en su blog sobre cómo encontrar a un buen esposo. Dice al respecto: "Muchas mujeres musulmanas, de todas partes del mundo, tanto las que han sido criadas siempre como musulmanas como las que hemos abrazado el islam posteriormente enfrentan hoy en día una situación que tiende a desalentarlas a momentos, me refiero específicamente a encontrar un buen esposo musulmán con quien casarse y completar la mitad de su fe." Musulmana ecuatoriana (octubre de 2011): Carta para mis hermanas en el islam, tanto casadas y solteras, Blogspot,
} 
en vías de expansión y que es una cuestión de tiempo el que un país como el Ecuador se convierta también en islámico.

La invitación de venir a casarse al El parece responder a un problema real. Las mujeres se quejan de que los hombres no cumplen con sus deberes religiosos y se dejan seducir por los placeres que les ofrecen los laxos sistemas sociales. El EI promete a las mujeres musulmanas imponer la ley de Dios para ambos sexos. Por consiguiente, esta promesa también puede atraer a las jóvenes que se encuentran en una situación tradicional conservadora que se presenta en general como más permisiva con los hombres. El perfecto Estado Islámico promete a las mujeres que se definen como musulmanas ideales, modestas y castas unos esposos tan modélicos como ellas. Esos serían hombres que alimentan a sus mujeres y a sus hijos, defienden a su familia y comunidad y cumplen con todas las reglas religiosas. Además, serían hombres que no se entretienen con los placeres vanos de este mundo sino dirigen toda su atención hacia el paraíso que conseguirán mediante el martirio.

\section{Bibliografía}

AL-GHAZALI, Zaynab (1981): Ayam min hayati, El Cairo, Dar ash-Shuruq.

CRESWELL, Robyn; HAYKEL, Bernard (11 de octubrea de 2014): "Battle Lines, Want to Understand the Jihadis? Read Their Poetry", The New Yorker,

https://www.newyorker.com/magazine/2015/06/08/battle-lines-jihad-creswell-and-haykel [consulta: 6 de febrero 2018].

GARCÍA-CALVO, Carola; REINARES, Fernando (16 de noviembre 2015): Terroristas, redes y organizaciones: facetas de la actual movilización yihadista en España, documento de trabajo 17/2015, Real Instituto Elcano,

KIZILHAN, Jan Ilhan, Cavelius (2017): Alexandra, Die Psychologie des IS: Die Logik der Massenmörder, Múnich, Europa Verlag.

MAALOUF, Amin (1991): Las cruzadas vistas por los árabes, Madrid, Alianza.

MARTín, Javier (2015): El Estado Islámico: Geopolítica del Caos, Madrid, Catarata.

PLEASANCE, Chris (31 de diciembre de 2014): "How to raise a jihadi-baby: Horrifying ISIS guide for mothers instructs them to ban TV to 'protect little ears', tell bedtime stories about fighting and give toddlers weapons training with toy guns", Mail Online, http://www.dailymail.co.uk/news/article-2891461/How-raise-jihadi-baby-Horrifying-ISIS-guidemothers-instructs-ban-TV-protect-little-ears-tell-bedtime-stories-fighting-toddlers-weaponstraining-toy-guns.html [consulta: 3 de enero de 2018].

RAYMOND, Ibrahim (11 de agosto de 2011): "Egypt: Why are Christian Girls Converting to Islam", Jihad Watch, https://www.jihadwatch.org/2011/08/raymond-ibrahim-egypt-why-are-christiangirls-converting-to-islam [consulta: 3 de febrero de 2018].

http://musulmanaecuatoriana.blogspot.de/2011/10/carta-para-mis-hermanas-en-el-islam.html [consulta: 7 de enero de 2018]. 
RODICIO, Ángela (2016): Las novias de la yihad, Valladolid, Editorial Espasa.

SIVAN, Emmanuel (1985): Radical Islam, Medieval Theology and Modern Politics, New Haven/Londres Yale University Press.

TORRES DÍAZ, Olga (2015): La propagada del DAESH también es cosa de mujeres. De Umm Sumayyah Al-Muhajira en Dabiq al manifiesto de la Brigada Al-Khansaa en internet, documento opinión 121/2015, Instituto Español de Estudios Estratégicos.

WINTER, Charlie (febrero de 2015): Women of the Islamic State, a Manifesto by the Khanssaa Brigade, Translation and Annotation, Londres, Quilliam Foundation.

WITHNALL, Adam (1 de enero de 2015): "Isis-Booklet Issues Guidelines to Mothers on How to Raise “Jihadi Babys', Independent, https://www.independent.co.uk/news/world/middle-east/isisbooklet-issues-guidelines-to-mothers-on-how-to-raise-jihadi-babies-9952721.html [consulta: 3 de febrero de 2018]. 